\title{
COLÉGIO GONZAGA: PIONEIRO E DIFUSOR DO ENSINO CATÓLICO NA CIDADE DE PELOTAS
}

\author{
Giana Lange do Amaral \\ UFPEL \\ giana@ufpel.edu.br
}

\section{RESUMO:}

Este texto apresenta aspectos da história do Colégio Gonzaga, criado pelos jesuítas, em 1894, como Escola São Luís Gonzaga, e que foi a primeira instituição católica de ensino primário e secundário da cidade de Pelotas. O Gonzaga foi, em diferentes épocas, um importante instrumento na disseminação da ideologia católica junto a meninos e rapazes. Sua ação educacional e evangelizadora deu-se inicialmente pela ação dos jesuítas e posteriormente, pelos lassalistas com importante atuação das associações religiosas que ali se formavam. O sistema de ensino pautado pelos princípios da disciplina, da obediência, do respeito e dos bons exemplos, tendo por base a inculcação moral e religiosa, visava à formação de alunos dóceis, obedientes, mas ao mesmo tempo preparados para ocuparem futuramente posições e responsabilidades de mando. Era uma escola destinada àqueles que podiam pagar e que se sujeitavam às suas regras bem definidas.

Palavras-chave: Instituição educacional. Educação católica. Projeto pedagógico lassalista.

\section{GONZAGA SCHOOL: PIONEER AND SPREADING OF CATHOLIC TEACHING IN THE CITY OF PELOTAS}

\begin{abstract}
:
This text presents aspects of the history of Gonzaga School, established by Jesuits in 1894 as São Luíz Gonzaga School, and that was the first Catholic institution of primary and secondary education in the city of Pelotas. Gonzaga was, at different times, an important tool in spreading the Catholic ideology with the boys and young men. Its educational and evangelizing action took place initially by the action of the Jesuits and later by the Lasallian, with important action of religious associations that were formed there. The education system guided by the principles of discipline, obedience, respect and good examples, based on the moral and religious inculcation, aimed the formation of docile, obedient students, but at the same time prepared to fill future positions and responsibilities of power. It was a school for those who could afford it and who subjected themselves to their well-defined rules.

Keywords: Educational institution. Catholic education. Lasallian pedagogical Project.
\end{abstract}

Nos meios acadêmicos brasileiros, o estudo das instituições educacionais vem ganhando espaço nos últimos anos. São inúmeros trabalhos que contribuem na elucidação e compreensão da História da Educação Brasileira, pois ao buscarem estabelecer o perfil de determinadas escolas, enfatizam aspectos da cultura escolar, exploram questões didáticopedagógicas, político-ideológicas, étnicas e de gênero em diferentes dimensões temporais e espaciais.

Nesse sentido, é que o presente texto se propõe a apresentar aspectos da história do Colégio Gonzaga, nas primeiras décadas de seu funcionamento na cidade de Pelotas. Nesta 
pesquisa, sigo alguns passos metodológicos indicados por Frigerio e Poggi (1996), no que se refere à análise da instituição escolar. Segundo essas autoras,

se considerarmos as instituições educativas como um objeto de conhecimento complexo, só pode-se apreender delas alguns aspectos, dos quais se delineiam a questão, também complexa, do "recorte" na análise da instituição educacional e das prioridades para a recopilação de informações e para seu processamento (FRIGERIO e POGGI, 1996, p. 40).

Assim, apontam caminhos de análise do território escolar, onde são tecidas estratégias de atuação do pesquisador junto aos arquivos e aos atores educacionais, ressaltando idéias sobre a difícil articulação do tempo e do espaço escolar.

Da mesma forma, alguns conceitos desenvolvidos por Nóvoa (1992, 1995), Magalhães (1996, 2005) e Werle (2004), respaldam aspectos teórico-metodológicos deste estudo. Segundo Nóvoa (1995, p. 25), a emergência de uma sociologia das organizações escolares privilegia um nível "meso" de compreensão e de intervenção. Está situado entre uma abordagem centrada na sala de aula - percepção "micro" - e as análises sócioinstitucionais focalizadas no sistema educativo - abordagem "macro". Este autor afirma que os estudos centrados nas características organizacionais das escolas tendem a construir-se com base em três grandes áreas: "a estrutura física da escola": dimensão da escola, recursos materiais, número de turmas, edifício escolar, organização dos espaços, etc.; "a estrutura administrativa da escola": gestão, direção, controle, inspeção, tomada de decisão, pessoal docente, pessoal auxiliar, participação das comunidades, relação com as autoridades centrais e locais, etc.; - "a estrutura social da escola": relação entre alunos, professores e funcionários, responsabilização e participação dos pais, democracia interna, cultura organizacional da escola, clima social, etc.

A partir dessa compreensão, abre-se a possibilidade da análise das instituições educativas através de "recortes" que priorizem determinados períodos ou aspectos que delineiem as questões de pesquisa.

Seguindo essa lógica, os estudos das instituições educativas, embora necessitem de um recorte que sirva como balizamento, deixam de ser uma narrativa de fatos que estejam estritamente organizados em função de uma cronologia fechada, mas sim, interrelacionados no tempo e no espaço. Há que se buscar em outros tempos e espaços traços, pistas e sinais que auxiliem na explicação das singularidades estudadas.

Para tanto, deve-se buscar conexão com as múltiplas fontes de pesquisa que transcendem o estudo de estatutos, planos globais ou diretrizes que regem a escola. Esses não bastam para definir realmente a concretude da escola, que resulta das manifestações implícitas e explícitas das relações que se estabelecem no seu interior e das relações com o poder constituído, seja ele político, econômico, cultural, social, ideológico. Nesse sentido, Nóvoa(1995, p. 16) defende que,

mais do que nunca, os processos de mudança e de inovação educacional passam pela compreensão das instituições escolares em toda sua complexidade técnica, científica e humana.

A identificação das margens da mudança possível implica a contextualização social e política das instituições escolares bem como a apropriação ad intra dos seus mecanismos de tomada de decisão e das suas relações de poder. As escolas constituem uma territorialidade 
espacial e cultural, onde se exprime o jogo dos actores educativos internos e externos; por isso, a sua análise só tem verdadeiro sentido se conseguir mobilizar todas as dimensões pessoais, simbólicas e políticas da vida escolar, não reduzindo o pensamento e a acção educativa a perspectivas técnicas, de gestão ou de eficácia stricto sensu.

Desta forma, considero fundamental o desenvolvimento de pesquisas sobre a História da Educação Brasileira, levando-se em conta as especificidades regionais e as singularidades locais e institucionais. Como afirma Magalhães (1996, p. 2):

Compreender e explicar a existência histórica de uma instituição educativa é, sem deixar de integrá-la na realidade mais ampla que é o sistema educativo, contextualizá-la, implicando-a no quadro de evolução de uma comunidade e de uma região, é por fim sistematizar e (re)escrever-lhe o itinerário de vida na sua multidimensionalidade, conferindo um sentido histórico [...] que envolve uma hermenêutica sutil de aprofundamento e de descoberta [...] que medeia entre a memória e o arquivo [...] onde se cruzam informações de várias naturezas - orais, arquivísticas, museológicas, arquitetônicas, fontes originais e fontes secundárias - um manancial de informação cuja exploração e utilização carecem de uma cuidada vigilância hermenêutica." (grifo nosso).

Muitos dos dados sobre o Colégio Gonzaga expostos a seguir têm por base levantamentos realizados pelos Irmãos Parmagnani e Ruedell que, em 1995, organizaram o Memorial do Colégio Gonzaga, editado em comemoração aos 100 anos desse estabelecimento escolar. Também foi fonte fundamental nas análises as "lembranças", que eram relatórios anuais que davam uma visibilidade das atividades e do andamento da vida escolar. Em 1899, foi publicado pela primeira vez o relatório com a premiação dos alunos em comportamento, aplicação, aproveitamento e melhor classificação nas notas das disciplinas. A partir da década de 1920 aparecem, nas "lembranças", fotos dos alunos premiados, dos participantes das associações católicas, do batalhão militar, das festas religiosas, das excursões, dos festivais teatrais e musicais e de autoridades civis e religiosas. Também há muitas fotografias dos prédios do Gonzaga, com tomadas de seus espaços internos e externos.

Com o objetivo de me aproximar do clima vivenciado naquele período, realizei entrevistas com pessoas ligadas à Instituição Educacional que analiso, partindo da orientação metodológica de autores que fundamentam a História Oral e o uso da memória na História da Educação. Esse procedimento, além de estimular o debate e alargar a problemática da investigação, permitiu que viessem à tona certos contextos e acontecimentos que se perderam no tempo.

Sobre esse tema destaco a leitura das coletâneas Usos e Abusos da História Oral, organizada por Ferreira e Amado (1998). Tomo por base a idéia das autoras, que consideram a História Oral como uma "metodologia" e não como uma "técnica" ou "disciplina”. Sendo assim, a História Oral

apenas estabelece e ordena procedimentos de trabalho - tais como os diversos tipos de entrevista e as implicações de cada um deles para a pesquisa, as várias possibilidades de transcrição de depoimentos, suas vantagens e desvantagens, as diferentes maneiras de o historiador relacionar-se com seus entrevistados e as influências disso sobre seu trabalho - funcionando como ponte entre teoria e prática (FERREIRA e AMADO, 1998, p. 16). 
Segundo as autoras, a História Oral é apenas capaz de "suscitar", mas jamais "solucionar" questões. Favorece a formulação de perguntas, mas não pode oferecer as respostas. As respostas devem ser buscadas na teoria (histórica, sociológica, psicanalítica, etc.), que agrupa conceitos capazes de pensar abstratamente os problemas metodológicos gerados pelo fazer histórico, tais como os conceitos de "história" e "memória", assim como as complexas relações entre ambos.

\section{A primeira instituição católica de ensino primário e secundário da cidade}

A reorganização das escolas católicas no Brasil foi uma importante arma no processo de reestruturação do catolicismo nos anos posteriores à implantação da República. E no Rio Grande do Sul este processo desenvolveu-se de forma singular e muito significativa, graças à ideologia do governo castilhista, que estimulava a iniciativa particular na área educacional. ${ }^{1}$

Dessa forma, são criados no estado, a partir da década de 1890, vários estabelecimentos de ensino católicos, dentre os quais, em 1894, a então Escola São Luiz Gonzaga, que foi a primeira instituição católica de ensino primário e secundário da cidade de Pelotas, obra do pioneirismo dos padres jesuítas Anselmo de Souza e Gustavo Locher ${ }^{2}$.

Os jesuítas chegaram à cidade em 1888. Nos primeiros anos, desenvolveram intensa atividade pastoral não só em Pelotas, mas, também, nos municípios vizinhos, encontrando condições adversas e pouca receptividade. Há relatos de que, nessa época, em Pelotas, a confissão era quase desconhecida e que na igreja matriz apenas uma senhora idosa comungava. Foi difícil a aceitação da atuação da Companhia de Jesus, não só nessa cidade, mas em toda zona da campanha gaúcha, devido à forte presença da Maçonaria e ao espírito anti-clerical reinante. Situação bem diferente da encontrada nas regiões de colonização alemã e italiana do estado, onde havia uma maior predisposição à aceitação das concepções "ultramontanas".

Sabe-se que em Pelotas o anti-clericalismo se manifestava, principalmente, através dos inúmeros órgãos da imprensa local que, através de acusações e campanhas difamatórias, hostilizavam abertamente a presença dos padres na comunidade pelotense.

Sendo assim, após alguns anos de árduas atividades, os jesuítas passaram a utilizarse de um meio bastante eficaz na complementação de sua ação pastoral: a educação escolar. Como afirmam Parmagnani e Ruedell (1995, p. 28):

O Padre Anselmo de Souza deu-se conta de que o melhor meio de reavivar o espírito cristão seria começar pelas crianças, abrindo uma escola de que faria seu quartel general (grifo nosso) sob a proteção de São Luiz Gonzaga.

Não tardou que as famílias se dessem conta do grande bem que a escola vinha realizando. Enfrentaram as chacotas, os motejos e até algo de pior por parte dos anticlericais, mas corajosamente confiaram seus filhos à nova Escola.

No fim do ano letivo, a matrícula passou dos 15 do primeiro dia, a um total de 92 alunos. O número não foi maior por absoluta falta de espaço. As instalações e a mobília eram deficientes. 
Como pode ser observado a seguir, nas primeiras décadas, de acordo com os relatórios anuais, o número de alunos que acorreram para o estabelecimento de ensino aumentou bastante: 1895, 62 alunos; 1900, 296 alunos; 1910, 349 alunos; 1920, 395 alunos; 1925, 508 alunos; 1940, 1228 alunos. O corpo docente, que inicialmente era composto por três padres, foi sendo acrescentado a cada ano que passava por outros professores, todos religiosos. Somente a partir dos anos de 1920 é que se constata a presença de professores leigos.

O método educacional dos jesuítas, que uniformizava a pedagogia por eles aplicada em toda a sua extensa rede de colégios, se fundamentava na Ratio Studiorum ${ }^{3}$, que definia critérios e organizava o conhecimento escolar. O sistema de ensino pautado pelos princípios da disciplina, da obediência, do respeito e dos bons exemplos, tendo por base a inculcação moral e religiosa, visava a formação de alunos dóceis, obedientes mas ao mesmo tempo preparados para ocuparem futuramente posições e responsabilidades de mando. Como afirma Dallabrida (2001, p. 164 e 165)

o regime do ginásio dos jesuítas e dos quartéis modernos era parecido, tendo em comum várias táticas e estratégias de regulação, sendo que no primeiro priorizava-se o aprimoramento intelectual, enquanto no segundo adestrava-se sobremaneira o corpo. Organizados em divisões os ginasianos eram vistos como soldados [...] a semelhança entre os soldados e os ginasianos foi reforçada pelo fato do currículo do colégio conter instrução militar, de modo que a formatura do bacharelado coincidia com a cerimônia de entrega da carteira de reservista.

As permanentes atividades propostas aos alunos, o controle do espaço e do tempo, a emulação e a premiação aos melhores alunos eram importantes dispositivos utilizados pelos jesuítas para atingirem os seus objetivos educacionais.

O método de ensino jesuítico previa avaliações freqüentes objetivando verificar o desempenho intelectual e inspecionar a conduta dos alunos. No Gonzaga, quatro vezes ao ano havia os "dias do boletim". O corpo docente e os alunos se reuniam no salão nobre do Ginásio e assistiam ao "ritual militar" da proclamação das notas. Aspectos desse ritual, amenizado por apresentações artístico-culturais que envolviam o teatro, a música, o canto e as declamações feitas pelos alunos, nos é relatado a seguir:

É como si o general e a officialidade passassem revista aos seus batalhões. Perante aquella assembléa cada alumno ouve publicar o seu muito ou pouco adeantamento e recebe o prêmio da sua applicação, ou talvez um estimulante menos agradável para a sua indolência natural. Como, porém, a leitura das notas de mais de 400 alumnos é bastante árida, costuma-se enfeitar este acto dos arabescos de música, canto, declamação e theatro.

A pequena orchestra do Gymnasio é, sem dúvida, o factor mais efficiente para amenizar as reuniões officiaes da casa e contribuir para a educação artística e o bom gosto dos alumnos. Nestas occasiões algumas aulas deram mostra apreciável do seu progresso na difícil arte do canto. Com bastante agrado o auditório acolheu sempre os pequenos declamadores e com merecido applauso os jovens oradores, dos quaes um ou outro um dia se torne celebridade da tribuna brasileira. O que, porém, despertava mais entusiasmo no auditório juvenil era o theatro com suas pequenas comédias que os alumnos representavam com naturalidade e graça empolgante. Toda a proclamação das notas é fechada com chave de ouro pelo Revmo. Pe. Reitor que com a 
eloqüência dos sentimentos paternaes, ora felicitando, ora estimulando os brios da mocidade, aponta-lhe a nova posição a tomar até que alcance a Victoria final na festa da conclusão do anno escolar" (LEMBRANÇA DO GYMNASIO GONZAGA, 1924, p. 96).

Os padres jesuítas do Gonzaga, desde 1910, passaram a ser auxiliados pelos irmãos maristas, os quais se responsabilizaram pelo curso primário da escola, até $1926 .{ }^{4}$ Nesse período, lecionaram naquela escola 15 irmãos maristas de origem francesa e alemã. A Companhia de Jesus dirigiu o Gonzaga até o ano de 1926, quando os Irmãos Lassalistas assumiram a sua direção, tarefa à qual se dedicam até o ano de 2003, quando o Colégio foi arrendado a empresários da cidade

Em 1924, por decisão dos superiores da Congregação Jesuítica na Alemanha para que a Ordem priorizasse sua atuação junto à formação eclesiástica, o Gonzaga esteve na iminência de fechar. Isso muito em função da eclosão da Primeira Guerra Mundial, que impediu a vinda de elementos de várias congregações para o nosso país, e fez surgir centros de formação de novos quadros que passaram a preparar as vocações religiosas de brasileiros.

O reitor do Gonzaga, demonstrando empenho pelo seu não fechamento, através de correspondência datada de 26.07.1925, tenta justificar ao provincial da Alemanha a importância estratégica de se manter um colégio destinado à formação da elite riograndense numa região onde predominava o latifúndio, de onde mais saíam quadros de influência na vida pública:

O Rio Grande do sul é o $3^{\circ}$ ou o $4^{\circ}$ em influência entre os estados do Brasil, muito revolucionário. $\mathrm{O}$ sul fornece muitos ministros, generais, etc., e para o Rio Grande do Sul, funcionários públicos graduados, médicos, advogados, engenheiros. Há muitos latifundiários. Nas colônias alemãs é tudo minifúndio e de lá não surgem pessoas de influência na vida pública. Mas, das 15 casas dos jesuítas, no Rio Grande do Sul, 13 estão nas colônias, 1 em Porto Alegre e 1 em Pelotas. Nas colônias há muitos outros religiosos e bom clero diocesano. No sul, em Pelotas, estamos nós, o bispo, seu secretário e mais 3 padres. $\mathrm{Na}$ campanha, 11 padres idosos, distantes entre si 10 a 20 horas a cavalo. E só os padres das colônias fizeram bom trabalho, salvando a fé desse povo. [...] Nossos internos têm tanta importância, provindo da campanha, como os 400 externos da cidade de Pelotas (PARMAGNANI e RUEDELL, 1995, p. 61)

Ficou então decidido que os Jesuítas, que se retiraram para Santa Maria, onde foram dirigir o Seminário Diocesano daquele Bispado, entregariam o Gonzaga para uma outra congregação religiosa masculina. Como aos maristas faltava pessoal para substituir com igual competência aos jesuítas, a administração dessa escola passou para os lassalistas, que inicialmente o alugaram e, em 1934, acabaram por comprá-lo dos jesuítas.

\section{Uma escola lassalista}

Os Irmãos lassalistas começaram suas atividades no Brasil na primeira década do século XX. Vindos em sua maioria da França, de onde tiveram muitos de seus colégios 
fechados pelo governo anti-clerical maçônico, aqui dedicaram-se também à ação educativa nas escolas. ${ }^{5}$

A pedagogia lassalista tem por fundamento os preceitos do educador católico São João Batista de La Salle. Conforme nos afirma Justo (1991, p. 7 e 8),

o fim supremo de La Salle, na educação, foi o ideal do Evangelho: "procurai primeiramente o reino de Deus". A formação moral e religiosa do educando por meio da instrução, do exemplo, da participação na Missa, da freqüência dos Sacramentos, da oração, ocupa o lugar primacial no seu sistema pedagógico. Imprescindível também considerava - embora the concedesse importância secundária - a educação intelectual, profissional, social e física. [...] Corolários: a obrigatoriedade escolar e a gratuidade do ensino para quem não tivesse condições de pagá-lo. [La Salle] generalizou o uso do modo simultâneo e a leitura na língua materna no curso primário e suavizou a severa disciplina da época. Abriu as primeiras escolas para a formação de professores leigos, organizou escolas dominicais, profissionais e de comércio.

Os lassalistas, que estavam no Rio Grande do Sul há 19 anos, ao virem para Pelotas, fecharam o internato de São José de Canoas, que se tornou uma casa de formação eclesiástica. Dos quase 200 internos alguns poucos se dispuseram a ser transferidos para o Gonzaga. Quando assumiram a direção, o Ginásio Gonzaga tinha 400 alunos externos e 68 internos. No sistema de internato, que vigorava desde 1916, os alunos eram dos cursos primários e secundários e estavam divididos em dois grupos, conforme sua idade.

Sabe-se que, desde 1922, a vinda dos lassalistas para a cidade já era pleiteada pelo bispo de Pelotas, D. Joaquim Ferreira de Mello para que administrassem o Asilo de Meninos Desvalidos por ele criado. Mas os Irmãos, de início, não demonstraram interesse nessa obra. Somente assumiram-na quando vieram para Pelotas para dirigir o Gonzaga. Ressalta-se que, até os dias de hoje, os lassalistas têm como prática, a partir de sua atuação em um estabelecimento educacional pago, ajudar na manutenção de uma escola gratuita.

Dessa forma, em Pelotas, assumiram a direção da Escola Sagrado Coração de Jesus, destinada a meninos, e junto da qual também funcionava o Asilo de Meninos Desvalidos. Parmagnani e Ruedell (1995, p. 89) lembram que:

desde os primórdios da congregação, La salle e, em continuação os Irmãos, fizeram da gratuidade do ensino para os pobres, prioridade para a ação educativa. [...] Mas já no tempo de La Salle, havia Escolas Pagas, isto é, mantidas pelas mensalidades dos alunos. Para salvaguardar o princípio de gratuidade, os Irmãos faziam e fazem questão de que o estabelecimento em que se recebia pagamento dos alunos mantivesse uma escola gratuita em bairro pobre, a que se chamava Escola Quartier. Houve três tentativas de se manter uma escola para pobres na zona portuária, dentro da paróquia do Sagrado Coração de Jesus. Primeiramente, os jesuítas, depois os maristas e, finalmente, de novo os jesuítas.

A Escola Sagrado Coração de Jesus funcionou até 1955, quando estabelecimentos de ensino público municipais e estaduais passaram a dar conta dos alunos até então atendidos por aquela escola comunitária. A Escola fechou em função de não ter havido acerto entre os Irmãos e o bispo D. Antônio Záttera quanto à sua manutenção e reformas 
que se faziam necessárias. Anos mais tarde, em 1964, os Irmãos criaram uma outra escola gratuita em um bairro pobre da cidade, a Escola e Assistência Social Hipólito Leite, aproveitando uma obra de assistência que fora iniciada no bairro Cruzeiro pela Irmã Maria Assunta Tacca. Hoje, a Escola atende a mais de 500 crianças carentes e continua a ter seus trabalhos coordenados pelos lassalistas.

Quando a direção do Gonzaga passou para os lassalistas, o Curso Primário continuou a existir, mas o Ginasial foi suprimido, sendo adotado em seu lugar o Curso Comercial, a "Escola Superior de Comércio anexa ao Ginásio Gonzaga". Isso em função de que já mantinham um Curso Comercial teórico e prático no Instituto São José de Canoas, tendo, portanto, um corpo docente bastante habilitado. E, também, devido à legislação da época que concedia a equiparação ao Ginásio D. Pedro II somente a estabelecimentos públicos de ensino, o que desoficializava os cursos preparatórios para ingresso no ensino superior existentes nos estabelecimentos educacionais particulares. ${ }^{6}$ Com essa mudança, embora tenha havido muitas desistências de alunos que freqüentavam o Curso Ginasial desse estabelecimento escolar, já em 1927 as matrículas nos Cursos Primário e Comercial deram um salto para mais de 800 alunos.

Em função da Lei Maximiliano, de 1915, a equiparação ao Colégio D. Pedro II passou a ser concedida somente a estabelecimentos públicos estaduais de ensino secundário. É importante dizer que esse foi um período em que as elites acorreram às escolas públicas uma vez que essas, através do sistema de equiparação, representavam o caminho mais rápido e seguro para ingressarem no ensino superior. No caso de Pelotas, a equiparação foi recuperada na segunda metade dos anos 20 pelo Ginásio Municipal Pelotense, o que fez com que boa parcela de jovens lá realizassem seus estudos de nível secundário. Era bastante comum que, na década de 1930, os alunos de classe social mais abastada realizassem o curso primário no Gonzaga e o secundário no Pelotense (que desde 1925 ministrava somente o ensino secundário). E aos alunos internos do Gonzaga, em sua maioria filhos de famílias de fazendeiros da região sul, restou habilitarem-se como "Peritos Contadores", que correspondia ao segundo ciclo do secundário. ${ }^{7}$

Dessa forma, o Gonzaga passou a oferecer um curso secundário que, embora não atendesse às expectativas das elites - sua principal clientela até então - fosse voltado para as necessidades prementes de mercado de trabalho ligado às atividades que mais cresciam na cidade, ou seja, as atividades comerciais, bancárias e de administração pública.

O Curso Comercial do Gonzaga, diferentemente do ensino clássico propedêutico que servia aos interesses dos que objetivavam o ensino superior - era mais prático, com conteúdos programáticos voltados para o desempenho de atividades comerciais, bancárias e da administração pública, preparando jovens para ingressarem de imediato no mercado de trabalho. Nesse Curso, o aluno recebia ensino teórico e prático através de um escritório modelo onde os jovens eram iniciados nas mais variadas "operações do comércio moderno".

Pelos depoimentos de alunos egressos do Gonzaga, tem-se uma idéia do ensino ministrado no Gonzaga nesse período. Clayr Rochefort, aluno do Gonzaga na década de 1940, comenta:

O Gonzaga distinguia-se não só por ministrar ensino de qualidade, mas também pela formação religiosa, ética e moral que procurava dar aos alunos. Eram dignas de nota a relação respeitosa e a disciplina reinantes no Colégio, em todas as situações. Estou certo de que essa influência me marcou para sempre.[...] Os tempos do Gonzaga estão vivos em minha memória. Recordo-os sempre com saudade, como se estivesse a escalar a íngreme escadaria de acesso à capela; a seguir em fila para as aulas; a 
desfrutar doces minutos de recreio; a bater bola às tardes de quartas e sábados no pátio, ou a suar a camiseta nos gramados da Chácara dos Padres, como era conhecida. Havia, também, nossa participação nos festivais e nos convescotes (piqueniques) de fim de ano. Era uma festa, uma alegria.

Em relação às aulas, para que se tenha uma idéia de como seria o que Parmagnani e Ruedell (1995, p. 130 e 131) consideram uma "aula tradicional no Gonzaga" nos anos 30 e 40, aponta-se o relato a seguir:

Uma sala vazia, vasta para 50 alunos bem acomodados. Na frente, um quadro negro, a escrivaninha do professor sobre o estrado de uns $35 \mathrm{~cm}$ de altura para bem dominar toda a classe.

No centro da parede, acima do quadro negro, a imagem do Sagrado Coração de Jesus e o Crucifixo. Tudo em perfeita ordem.

A porta abre-se. Um irmão de batina preta e colarinho branco entra e vai direto à sua mesinha. Pouco depois, chegam os alunos. Vão entrando e ocupando seus lugares quase em silêncio. O Irmão, de pé, recebe-os com um sorriso e corresponde com leve inclinação aos que o saúdam. Estão todos de pé. Silêncio. Faz-se uma breve oração. Todos se sentam e não têm nada sobre a mesinha. O Irmão, com voz clara, palavras bem espaçadas, inicia a lição. Os olhares dos 50 alunos estão cravados nele, pelo menos no começo.[...] O professor serve-se do quadro e giz e assim vai prosseguindo a explicação. Concluída, ele diz: "Tomem o livro...página...". Então é feita a leitura da lição explicada, em voz alta, geralmente alternando-se os alunos em cada parágrafo. Há interrupções para verificar se os alunos entendem todas as palavras e o conteúdo. Terminada a leitura, são feitas perguntas de modo que os alunos no fim já quase saibam a lição. [...] Quando o relógio dava horas, um aluno, de súbito, punha-se de pé e bem alto dizia: "Lembremo-nos que estamos na Santa presença de Deus". E todos os alunos, interrompiam seu trabalho, o professor se recolhia em oração e todos respondiam "Adoremos o Senhor.

Fora do espaço da sala de aula, os alunos eram fiscalizados pelos prefeitos, que eram Irmãos responsáveis pela disciplina e controle de suas atividades na escola. Havia o prefeito dos alunos internos e dos alunos externos.

Os prefeitos encarregados da disciplina realizavam a vigilância geral da escola, estando num posto hierarquicamente inferior ao do diretor geral. Acompanhavam os alunos nos corredores, nos recreios, nos jogos, nas salas de estudo, nos dormitórios e refeitórios e em seus passeios. A sua maior vigilância recaía sobre os alunos internos que, juntamente com aqueles que participavam mais ativamente da vida religiosa da escola, eram considerados a elite, os "alunos ideais". 8

Nos relatórios anuais pode-se perceber que os Irmãos reconheciam e viam como necessário o duro sistema de vigilância e disciplina que vigorava no internato. Ele era necessário para que imperasse a "ordem e a boa educação". Esse sistema nem sempre foi bem aceito pelos alunos e chega a causar estranheza a maneira como a resistência a ele, por parte dos alunos, nos é relatada: 
AGOSTO - vários pensionistas dão baixa do Pensionato em busca de maior liberdade. Repete-se a história do lobo montanhês e do cão doméstico: 'Prefiro padecer fome e privações mas correndo livremente pelos montes e campinas a estar gordo e bem tratado com uma corrente no pescoço' (LEMBRANÇA DE 1938, p. 10:))..

Como os alunos do Gonzaga, especialmente os internos, estavam submetidos a um exigente regime de cobrança intelectual e disciplinar, eram-lhes proporcionados alguns passeios ao longo do ano. Geralmente visitavam propriedades rurais pertencentes a parentes dos alunos ou a pessoas ligadas à Igreja. Essas saídas envolviam recreação e atividades físicas que propiciassem o desenvolvimento moral dos rapazes, fortalecendo a "educação do caráter juvenil". Nas "Lembranças" há relatos extensos e detalhados, inclusive com fotografias, desses momentos de "lazer construtivo", passando-nos uma idéia de que a escola não era somente um espaço que aprisionava os alunos para "despejarlhes" conhecimentos.

Além desses passeios esporádicos, semanalmente os alunos iam a pé para a "chácara dos padres". 9 A chácara, adquirida em 1920 pelos padres jesuítas e ampliada pelos lassalistas chegou a ter 14 hectares. Nesse local, com belas alamedas de eucaliptos, onde os Irmãos plantavam hortaliças e criavam vacas leiteiras, havia espaços para os alunos praticarem o esporte que era mais incentivado no Gonzaga, o futebol. Flávio Kramer, aluno do Gonzaga na década de 1950, nos conta:

quando nós íamos à chácara dos padres não tinham nem instalações para se mudar ou tomar banho. Havia uns dois ou três campos de futebol. Quando jogávamos uma peleja de futebol no sol e cansávamos, a gente descansava ali na sombra dos eucaliptos, tomando água muito boa, cristalina, do córrego que hoje é o poluidíssimo "canal do Pepino.

A emulação e o sistema de premiação foram fundamentais no projeto pedagógico dos lassalistas. O Gonzaga chegou a conceder medalha de ouro ao aluno que obtivesse, na conclusão do curso, o primeiro lugar no conjunto das matérias e medalha de prata, ao que obtivesse segundo lugar. O "prêmio de mais alta distinção" era conferido àqueles que obtivessem, em cada aula, os primeiros lugares no conjunto das disciplinas: distinção de $1^{\circ}$ grau, uma medalha de honra aos dois primeiros; distinção de $2^{\circ}$ grau, menção honrosa aos três seguintes. $\mathrm{O}$ "prêmio de excelência" era oferecido pelo excelente Comportamento e Aplicação demonstrado durante o ano todo: $1^{\circ}$ grau, uma medalha de honra ao primeiro; $2^{\circ}$ grau, menção honrosa aos quatro seguintes. O prêmio de Aproveitamento era atribuído àqueles que obtivessem o primeiro lugar numa ou mais disciplinas da aula. Assim como os premiados pelo Comportamento e Aplicação, os premiados pelo Aproveitamento tinham publicado o seu "retrato" no quadro de honra da "Lembrança". O "diploma de honra" era conferido aos alunos que conseguissem "nota de honra" durante todo o ano letivo. Havia, também, os Prêmios de Português, Matemática, Contabilidade, que consistiam em uma medalha de honra oferecida aos melhores alunos de cada turma. O Prêmio de Francês era oferecido pela "Liga da União Latina" aos alunos melhor classificados no Concurso que se realizava em fins de novembro. Em cada aula era dada uma medalha de honra ao aluno que se destacasse em Religião. Os alunos melhor classificados no "concurso final de Catecismo" também eram premiados.

Sobre os Concursos de Catecismo assim se manifestou Francisco Vidal, que estudou no Gonzaga em 1940: 
O diretor chegava de inopino e dizia: "vamos fazer um concurso de catecismo". Todos nos erguíamos. Ficávamos de pé, formando fila em torno da aula e ele ia indagando e a gente respondendo. Depois ele selecionava. Mais adiante no fim do ano a pessoa tinha que saber as perguntas e respostas. Eu me lembro de um campeoníssimo que foi o Osvaldo Bachi, que depois de todos cairmos ele ficou sozinho e foi até o fim do livro com ele" na cabeça". No fim do ano o bispo participava da prova final. Até que depois consideraram que não era mais conveniente uma coisa dessas, uma competição em torno do saber sobre religião... Acharam por bem que não era o melhor fazer competição em torno do seu saber teórico.

Pelo que nos é relatado, pode-se constatar o espírito competitivo do qual se revestia esse "certame catequético":

"No dia 29 de novembro realizou-se o grande "CONCURSO DE CATECISMO" para a conquista do título máximo de CAMPEÃO no período de 1938. Ás 10 horas reuniram-se no Palco do Salão os "campeões" das aulas que iam participar deste importante certame catequético: as respectivas aulas achavam-se na platéia para assistir à pugna de seus representantes e ao mesmo tempo para "torcer" por eles [...]. Presidiu a sessão da Diretoria do Ginásio e o zelosíssimo Pe. Capelão. A luta foi terrível: alguns caíram nas primeiras rodadas ao passo que outros resistiram tenazmente a várias dezenas de perguntas e respostas durante mais de uma hora, até que o distinto aluno Luiz Fernando Crespo de Souza, da $1^{\text {a }}$ série $B$, conseguiu vencer a renhidíssima peleja, sagrando-se gloriosamente "CAMPEÃO DE CATECISMO" do ano de 1938. Um artístico quadro representando a agonia de Jesus foi, além dos inúmeros aplausos e felicitações dos presentes, a recompensa que coube ao triunfador.( LEMBRANÇA DE 1938, p. 98).

Mesmo que o Gonzaga estivesse sob orientação lassalista, pode-se aproveitar a constatação de Dallabrida (2001, p. 265), que estudou Ginásio Catarinense dos jesuítas, quando o autor afirma que

a emulação e o sistema de premiação também eram peças fundamentais da engrenagem escolar, pelo fato de manterem acesa a chama da disputa, que catalisava a produtividade escolar. A otimização do forte ritmo de trabalho escolar era proporcionada por pausas produtivas, programadas e distribuídas adequadamente ao longo do dia, da semana e do ano escolar, na forma de recreios, jogos, festas, piqueniques, banhos de mar, passeios.

\section{A vida religiosa no Gonzaga}

Pode-se afirmar que a expressão objetiva e palpável do espírito religioso gonzagueano era a freqüência aos sacramentos e o florescimento e desenvolvimento das associações pias entre o corpo discente. Um panorama sobre a vida religiosa dos alunos e a ação educacional dos Irmãos Lassalistas dez anos após terem assumido o Gonzaga nos é relatado a seguir a partir da correspondência do Padre Lenz, capelão responsável pela direção espiritual dos alunos e dos Irmãos daquela escola, datada de $1936^{10}$ : 
Temos no Ginásio 700 alunos dos quais 70 são internos. Vou para lá todos os dias às $5 \mathrm{~h} 30 \mathrm{~min}$. Às $6 \mathrm{~h}$ é a comunidade dos Irmãos. Às 6h30min algumas confissões dos alunos internos. A seguir rezo um pouco de breviário e mais algumas confissões (dos alunos externos). Às 8h, missa para todos. Desde o princípio da missa, enchem-se todos os bancos, ao todo 28 com 7 a 8 assistentes por banco. $O$ espaço da entrada é tomado de imediato e, muitas vezes, o corredor diante da capela. De ordinário, as comunhões são 25 a 30; por vezes, 50 a 70. [...] Os grandes são precisamente os mais fiéis. Da $5^{\mathrm{a}} \mathrm{B}$ aparecem todos pelo menos uma vez por semana, sendo que os da $5^{\text {a }} \mathrm{A}$, são mais indolentes. Aos domingos dos últimos tempos, até se faz preciso fechar a porta logo após o primeiro sinal, porque a capela não comporta todos os rapazes. (PARMAGNANI e RUEDELL, 1995, p. 96 e 97)

É importante lembrar que aos alunos era obrigatória a freqüência às missas dominicais, momento em que tinham, inclusive, sua presença fiscalizada pelos Irmãos. Mas, durante a semana, estavam desobrigados dessa prática. Como as aulas no Gonzaga tinham início às $8 \mathrm{~h} 30 \mathrm{~min}$, muitos antecipavam sua chegada e assistiam às missas diárias na capela da escola. Percebe-se, dessa forma, o quanto, entre os alunos, fora assimilada a pedagogia de La Salle, que também fundamentava a formação moral e religiosa do educando através da sua devoção, que se manifestava na participação nas missas, frequiência nos sacramentos e oração. Em articulação com as missas, a confissão e a comunhão se incorporavam nas práticas educativas diárias dos estudantes. Através da escola recebiam solenemente, com a presença do bispo, a primeira comunhão, a crisma e até mesmo o batismo.

Os alunos da $5^{\mathrm{a}}$ série a que se refere o capelão eram concluintes do curso ginasial. Naquela época, vigorava o currículo de 10 anos, sendo que 4 anos correspondiam ao Curso Primário, 1 ano ao Curso de Admissão e 5 anos ao Ginásio. Esses alunos "grandes" tinham, provavelmente, entre 16 e 20 anos.

Em suas correspondências, Padre Lenz comenta sobre as aulas de Religião ministradas diariamente aos alunos de todas as séries. Conforme a opinião do Padre, os rapazes do Gonzaga eram diferentes daqueles que com ele conviveram no Ginásio Catarinense:

Aqui os alunos, também os da $5^{\text {a }}$ série, têm cada dia aula de Religião e
estas aulas preparadas pelos Irmãos com uma consciência admirável.
Devem fazer eles mesmos exames bem rigorosos de Religião:
Dogmática, Apologética e Ascética. Vi os programas. [...] Aqui ocorreu
sem alterações todo o ano. A opinião que formei, vindo para cá, foi-se
firmando sempre mais. Os meninos de Pelotas são de outra raça, muito
mais generosos e nobres que os de Florianópolis. São menos ingratos,
menos preguiçosos e menos mal criados. Encontrei aqui meninos os
quais nunca encontrei lá (PARMAGNANI e RUEDELL, 1995, p. 97).

A disciplina de Religião, embora fosse facultativa, conforme a indicação da legislação federal, figurava entre aquelas em que os alunos concorriam para o recebimento de premiação. Além das aulas de religião, ministradas pelos Irmãos, o capelão jesuíta também se encarregava de realizar visitas esporádicas às salas de aula para palestrar sobre temas de interesse doutrinário católico. 
Ao corpo discente era também propiciado o aprofundamento de seus conhecimentos sobre o catolicismo e vivência cristã através da participação nas associações católicas como as Congregações Marianas, Juventude Estudantil Católica, Apostolado da Oração e também diversos retiros espirituais dos quais geralmente participavam jovens ligados à Juventude Estudantil Católica.

As associações católicas de alunos, até meados da década de 1960, eram dispositivos pedagógicos bastante comuns nas escolas que pertenciam a diversas congregações religiosas.

Desde os primeiros anos do século XX, sabe-se da existência da Congregação Mariana que se destinava, inclusive, à participação de ex-alunos que, ao saírem do Gonzaga, continuavam fiéis à prática da Religião e à Congregação. Em 1924, foram criadas duas Congregações independentes: uma para os alunos internos - "Nossa Senhora do Rosário" - e outra para os externos -"Nossa Senhora da Glória".

Com os lassalistas no Gonzaga, as Congregações Marianas, sob a orientação dos padres capelães jesuítas, continuaram a cumprir com seus objetivos de estimular os congregados a serem modelos de aplicação, procedimentos, moralidade e obediência, através da fervorosa prática dos deveres religiosos e do bom encaminhamento para uma vivência cristã na vida social. Os congregados participavam de conferências cujos temas eram sempre considerados altamente morais e educativos. Realizavam reuniões semanais, participavam de devoções específicas e colaboravam com a organização e apresentação das festas religiosas que anualmente faziam parte do calendário escolar, dando-lhes um brilho especial. Dentre elas, a de São João Batista de La Salle, no dia 15 de maio, a Procissão de Corpus Christi, a festa de São Luiz Gonzaga, em 21 de junho, a festa do Coração de Jesus, as cerimônias de primeira comunhão e crisma dos alunos e as festas titulares das congregações de N. S. da Glória, N. S. do Rosário e N. S. da Conceição.

Essas associações contavam com uma diretoria, eleita pelos alunos, composta por diversos cargos: diretor espiritual (padre capelão), prefeito, $1^{\circ}$ e $2^{\circ}$ assistentes, secretário, tesoureiro bibliotecário e consultores.

No Gonzaga, cada associação religiosa tinha sua própria diretoria e seus programas de atuação. Por vezes dividiam seus trabalhos em seções como por exemplo:

- Congregação do SS. Menino Jesus, fundada em 1927, formada por meninos dos Cursos Preliminares, tendo por objetivos

alcançar de Deus, pela meditação do Menino Jesus, 1) que em todas as casas de educação Deus tenha o primeiro lugar; 2) que em toda parte e em todo o tempo tanto os professores como os alumnos possam livremente observar as leis de Deus e da Igreja; 3) que os meninos não sejam expostos a perder a fé naquellas escolas onde Deus é menos honrado; 4) que Deus seja servido em suscitar numerosas vocações para professores christãos e educadores religiosos" (LEMBRANÇA DO GYMNASIO GONZAGA, 1930, p. 75).

- Grêmio São Tarcísio, fundado em 1930, tinha por finalidade: a devoção especial e íntima união com Cristo Sacramentado, assim como a contribuição para a piedade e esplendor do culto divino, servindo aos turnos do altar, preparando os "coroinhas".

- Conferência Vicentina, fundada em 1928. Segundo seus relatórios, visava ao atendimento material e espiritual a famílias carentes através da distribuição de gêneros alimentícios e agasalhos, livros, brochuras e jornais "para fazer frente aos inimigos da fé católica e para a propagação da mesma”. 
- Cruzada Eucarística, fundada quando os jesuítas ainda administravam o Gonzaga. Funcionava em todas as classes do Gonzaga, havendo em cada uma, diretoria própria, eleita no início do ano, tendo por objetivo o incentivo a todos os alunos à comunhão freqüente.

- Centro de Juventude Católica, fundado em 1934. Baseado nos princípios de vida espiritual intensa, espírito de renúncia e de disciplina, seus membros objetivavam apostolizar a juventude.

Portanto, essas associações religiosas visavam, além do aprofundamento do conhecimento da doutrina católica, o desenvolvimento de uma ação apostólica interna que acabava por contribuir para a consolidação do projeto político-pedagógico da Igreja, exercendo o importante papel de regulação da vida escolar. Esses grupos representavam um papel fundamental no conjunto de estratégias e táticas didáticas utilizadas pelos lassalistas para alcançar a produção e obediência do corpo discente.

É preciso reconhecer que os alunos participantes dessas agremiações constituíam-se em uma elite, um modelo de conduta a ser seguido pelos demais. É notório que recebiam um tratamento diferenciado por parte dos Irmãos, que lhes propiciavam muitos passeios, jogos, piqueniques e viagens que objetivavam, além do "lazer saudável e familiar", maior união e comprometimento do grupo:

mas não é só pelas festas celebradas com edificante piedade, pelos festivais e pelas excursões que os congregados se distinguem. Em dez das quatorze aulas dos cursos secundário e comercial onde eles são recrutados, os primeiros prêmios foram conquistados brilhantemente por membros destas abençoadas agremiações marianas. Franca piedade, sã alegria, dedicação ao estudo: três substantivos que caracterizam os diletos "filhos de Maria" (LEMBRANÇA DO GINÁSIO GONZAGA, 1937, p. 126).

A participação dos alunos nesses grupos organizados servia de estímulo à adesão aos princípios do catolicismo e à normalização disciplinar. Muitas eram as táticas de vigilância e avaliação que levavam aos alunos o desejo de vencer e superar-se, resultado das recompensas oferecidas através das solenes premiações e/ou das pequenas recompensas diárias.

À avaliação dos conhecimentos adquiridos nas disciplinas, que se dava através de provas e exames regulados pela legislação nacional, somava-se à avaliação do comportamento escolar dos alunos. Esse tinha por base sua conduta em relação à interiorização das normas institucionais vigentes, especialmente as religiosas.

Pode-se afirmar que essa avaliação do desempenho comportamental dos alunos, no qual se incluía a assunção dos valores e princípios do catolicismo (participação nas associações religiosas, missas, sacramentos e retiros) é um aspecto fundamental não só para caracterização da identidade do corpo discente do Gonzaga, mas também de toda essa instituição escolar. É esse o ponto que afasta essa Escola da uniformização curricular imposta pelo sistema de equiparação, conferindo-lhe uma cultura escolar própria e uma identidade peculiar.

\section{Palavras finais}

Como se constata, o Gonzaga foi, em diferentes épocas, um importante instrumento na disseminação da ideologia católica junto a meninos e rapazes de vários segmentos 
sociais. Sua ação educacional e evangelizadora se dava inicialmente pelos jesuítas e posteriormente, através da atuação dos Irmãos lassalistas nos cursos do próprio Gonzaga e nas associações religiosas que ali se formavam, compostas pelos alunos de classes sociais de maior poder aquisitivo. Em contrapartida, sua ação se desenvolvia também através do trabalho dos Irmãos junto à escola gratuita que mantinham para atender alunos carentes e da atividade caritativa e evangelizadora dessas associações de leigos. Essa escola, no entanto, oferecia ensino somente primário, como "bem deveria ser" o ensino destinado às classes populares.

Dessa forma, propunham-se a educar novas gerações formando, junto às elites, lideranças católicas que se dirigiam aos cursos superiores e que se encaminhariam como profissionais liberais ou trabalhadores em empresas privadas ou órgãos públicos. E, junto às classes menos privilegiadas, visavam a formação de "bons trabalhadores", obedientes e responsáveis em relação às suas obrigações cristãs. Essa era uma forma de reforçar o habitus de cada classe através da existência de duas escolas específicas onde eram ministrados diferentes saberes e práticas escolares. Buscavam, assim, vincular o catolicismo à organização social, cultural, econômica e política da comunidade pelotense. Os Colégios religiosos, tanto os pagos quanto os gratuitos, visavam à formação de indivíduos letrados, católicos, patrióticos, ordeiros, dóceis e úteis, enquadrados à sua classe social.

Tendo por base depoimentos de ex-alunos sobre aspectos curriculares e organizacionais, o Gonzaga poderia ser definido como "uma escola organizada onde tudo funcionava muito bem", com uma disciplina exemplar, imposta pela vigilância e autoridade dos Irmãos. Uma escola que propiciava um "meio seguro de aprendizagem e formação" num prédio com dependências amplas e modernas. Uma escola cristã destinada àqueles que podiam pagar e que se sujeitavam às suas regras bem definidas, em relação ao processo de ensino no qual se incorporava a formação religiosa e comportamental oferecida aos alunos.

\section{Referências}

AMARAL, Giana Lange do. O Gymnasio Pelotense e a Maçonaria: uma face da história da educação em Pelotas. Pelotas: Seiva Publicações, 1999. (Série História da Educação em Pelotas, $\left.\mathrm{n}^{\mathrm{o}} 1\right)$.

AZZI, Riolando. História da educação católica no Brasil. Contribuição dos Irmãos maristas: 1887-1987. São Paulo, Simar, 1997.

BOURDIEU, Pierre. Economia das trocas simbólicas. $3^{\text {a }}$ ed. São Paulo: Perspectiva, 1992.

CAMPAGNONI, Ivo Carlos. História dos Irmãos lassalistas no Brasil. Canoas: Editora La Salle, 1980.

CERTEAU, Michel de. A escrita da história. Rio de Janeiro: Forense Universitária, 1982.

CHARTIER, Roger. Textos, impressão e leitura. In: HUNT, Lynn. A nova história cultural. São Paulo: Martins Fontes, 1992.

CHARTIER, Roger. História Cultural: entre práticas e representações. Lisboa: Difel, 1990.

CORSETTI, Berenice. Controle e ufanismo - A escola pública no Rio Grande do Sul (1889/1930). In: História da Educação/ASPHE. FaE/UFPel. № 4, set.1998. Pelotas. Ed. da UFPel. 
DALLABRIDA, Norberto. A fabricação das elites: o Ginásio Catarinense na primeira república. Florianópolis: cidade Futura, 2001.

DE CERTEAU, Michel. A operação histórica. In: Lê GOFF e NORA, Pierre (Orgs.). História: novos problemas. Rio de Janeiro: Francisco Alves, 1995b.

FERREIRA, Marieta e AMADO, Janaína (Coord.). Usos e abusos da história Oral. Rio de Janeiro: Ed. da Fundação Getúlio Vargas, 1998.

FRAGO, Antonio Viñao Del espacio escolar y la escuela como lugar: propuestas y cuestiones. Historia de la Educación, v. 13-14, p. 17-74, 1993-1994.

FRAGO, Antonio Viñao, ESCOLANO, Augustin. Currículo, Espaço e subjetividade: a arquitetura como programa. Rio de Janeiro: DP\&A, 1998.

FRANCA, Leonel, S.J. O método pedagógico dos jesuítas - o "Ratio Studiorum": introdução e tradução. Rio de Janeiro:.Livraria Agir Editora, 1952.

GIOLO, Jaime. Estado, Igreja e Educação no RS da Primeira República. São Paulo: USP, 1997. Tese de Doutorado em História e Filosofia da Educação - Faculdade de Educação, Universidade de São Paulo.

HALBWACHS, Maurice. A memória coletiva. São Paulo: Ed: Vértice, 1990.

HENGEMÜLE, Edgard, fsc. La Salle, uma leitura de leituras: o padroeiro dos professores na história da educação. Centro Universitário La Salle, 2000.

JUSTO, Henrique. La Salle, Patrono do Magistério - Vida, bibliografia, pensamento, obra pedagógica. $4^{\mathrm{a}} \mathrm{ed}, 1991$.

LE GOFF, Jacques. A História Nova. São Paulo: Martins Fontes, 1995.

LE GOFF, Jacques. História e Memória. $4^{\mathrm{a}}$ ed. Campinas, SP: Editora da UNICAMP, 1996.

LEMBRANÇAS DO GINÁSIO GONZAGA - 1910 A 1940.

LOCHER, Gustavo. Vade Mecum Philosophico. São Paulo, Typographia Brazil de Carlos Gerke, 1898.

MAIA, Pedro. Ratio Studiorum - Método Pedagógico dos Jesuítas. São Paulo, Loyola, 1986.

MAGALHÃES, Justino. Contributo para a História das Instituições Educativas - entre a Memória e o Arquivo. Universidade do Minho (mimeo), 1996.

MAGALHÃES, JUSTINO. A história das instituições educacionais em perspectiva. In: GATTI JR, Décio; INÁCIO FILHO, Geraldo. História da Educação em Perspectiva: ensino, pesquisa, produção e novas investigações. Campinas, SP: Ed. Autores Associados, Uberlândia, EDUFU, 2005. p. 91 a 103. 
NAGLE, Jorge. Educação e sociedade na primeira república. São Paulo, EPU. Ed. Da Universidade de São Paulo, 1974.

NÓVOA, António (org.). As Organizações Escolares em Análise. $2^{\circ}$ ed. Lisboa, Portugal: Publicações Dom Quixote, 1995.

PARMAGNANI, Irm. Jacob José, RUEDELL, Otto. Memorial do Colégio Gonzaga - Cem anos de Educação. Porto Alegre: Gráfica Editora Pallotti, 1995.

ROMANELLI, Otaíza de Oliveira. História da Educação no Brasil (1930/1973). 18ed. Petrópolis, RJ: Editora Vozes Ltda, 1996.

SAVIANI, Dermeval; LOMBARDI, José Claudinei; SANFELICE, José Luís (Orgs.). História e História da Educação: o debate teórico-metodológico. Campinas, SP: Autores Associados: HISTEDBR, 1998. (Coleção Educação Contenporânea).

SAVIANI, Dermeval. História da idéias pedagógicas no Brasil.Campinas, SP: Autores Associados, 2007.

TAMBARA, Elomar. Positivismo e Educação - Educação no Rio grande do Sul sob o Castilhismo. Pelotas, RS: Ed. Universitária, UFPel, 1995

VEIGA, Cyntia Greive. História da Educação. São Paulo: Ática, 2007

WERLE, Flávia . História das instituições escolares: de que se fala?. In: LOMBARDI, C.;NASCIMENTO, M. (orgs.). Fontes, história e historiografia da educação. Campinas, SP: HISTEDBR, PUCPR, UNICS, UEPG, 2004. p. 13 a 35.

Notas:

\footnotetext{
${ }^{1}$ Ver sobre o assunto, entre outros, Tambara (1995), Corsetti (1998) e Giolo (1997).

${ }^{2}$ O padre Locher, em sua passagem pela cidade, escreveu o livro Vade Mecum Philosophico, em 1898, abordando aspectos da concepção ideológica hegemônica no sistema educacional católico rio-grandense de então. Tal obra é um importante subsídio para o esclarecimento de questões que se referem às posturas dos jesuítas no campo educacional. Sobre a educação jesuítica ver, também, Franca (1952) e Maia (1986).

${ }^{3}$ A Ratio Studiorum era o plano completo de estudos mantidos pela Companhia de Jesus. Sobre esse assunto ver Franca (1952), Maia (1996) e Tambara (1995).

${ }^{4}$ Sobre a atuação dos Irmãos maristas no campo educacional, ver Azzi (1997).

${ }^{5}$ Sobre as idéias educacionais e a obra de São João Batista de La Salle, ver Justo (1991), e sobre a história dos Irmãos lassalistas no Brasil, Campagnoni (1980). Em Hengemülle (2000) são abordadas diversas leituras que os historiadores da educação efetuaram sobre o educador e pedagogo João Batista de La Salle.

${ }^{6}$ Sobre o assunto ver Nagle (1974).

${ }^{7}$ A Reforma Francisco Campos, através de decreto $n^{\circ} 20.158$, de 30.06.1931, organizou o ensino comercial nos níveis médio e superior e regulamentou a profissão de contador. Pelo decreto, os cursos ficaram assim estruturados: Cursos médios: $1^{\circ}$ ciclo (curso propedêutico, de 3 anos e curso de auxiliar de comércio, de 2 anos); $2^{\circ}$ ciclo (cursos técnicos de secretário, de 1 ano; guarda-livros, de 2 anos; administrador-vendedor, de 2 anos; atuário, de 3 anos; perito contador, de 3 anos); Curso Superior de Finanças ( 3 anos). (ROMANELLI, 1996, p. 139).
} 
${ }^{8}$ Sobre o sistema disciplinar e de vigilância no cotidiano de uma escola católica, consultar Dallabrida (2001).

${ }^{9}$ Em seu estudo sobre o Ginásio Catarinense, de orientação jesuítica, Dallabrida (2001) faz menção à existência de uma chácara dos padres em Florianópolis. Constata-se, dessa forma, a importância dada pelas escolas de orientação católica a atividades realizadas ao ar livre, reflexo, inclusive, das políticas higienicistas da época.

${ }^{10}$ Mesmo após ter-se retirado do Gonzaga, a Companhia de Jesus continuou a manter um padre para dar assistência religiosa à capelania da escola. O Padre Brentano (capelão de 1928 a 1932) foi fundador do Círculo Operário Pelotense; o Padre Lenz (capelão em 1936),ex-provincial dos jesuítas, veio transferido do Ginásio Catarinense, Florianópolis, onde exercia o cargo de Prefeito de disciplina; o padre Jaime Chemello (capelão em 1960 e 1961) foi bispo de Pelotas e presidente da CNBB - Conferência Nacional dos Bispos do Brasil.

Artigo recebido em: 20/10/2009

Aprovado para publicação em: 09/02/2010 